\title{
Maturity status effects on torque and muscle architecture of young soccer players
}

Giovani dos Santos Cunha, Marco Aurélio Vaz , Walter Herzog , Jeam Marcel Geremia , Gabriela Tomedi Leites \& Álvaro Reischak-Oliveira

To cite this article: Giovani dos Santos Cunha, Marco Aurélio Vaz, Walter Herzog, Jeam Marcel Geremia , Gabriela Tomedi Leites \& Álvaro Reischak-Oliveira (2020) Maturity status effects on torque and muscle architecture of young soccer players, Journal of Sports Sciences, 38:11-12, 1286-1295, DOI: 10.1080/02640414.2019.1589908

To link to this article: https://doi.org/10.1080/02640414.2019.1589908

曲 Published online: 21 Mar 2019.

Submit your article to this journal 준

LII Article views: 393

Q View related articles $\square$

View Crossmark data 4

Citing articles: 2 View citing articles ๘ 


\title{
Maturity status effects on torque and muscle architecture of young soccer players
}

\author{
Giovani dos Santos Cunha $\mathbb{1}^{\mathrm{a}}$, Marco Aurélio Vaz ${ }^{\mathrm{a}}$, Walter Herzog ${ }^{\mathrm{b}}$, Jeam Marcel Geremiac, Gabriela Tomedi Leites \\ and Álvaro Reischak-Oliveira ${ }^{a}$
}

aSchool of Physical Education, Physiotherapy and Dance, Exercise Research Laboratory, Universidade Federal do Rio Grande do Sul, Porto Alegre, Brazil; 'baculty of Kinesiology and Department of Mechanical and Manufacturing Engineering, University of Calgary, Calgary, Canada; 'Center for Physical Education and Sports, Universidade Federal de Santa Maria, Santa Maria, Brazil

\section{ABSTRACT}

This study investigated the effects of maturity status on knee extensor torque and vastus lateralis architecture of young soccer players. Thirty-four males aged 13-18 years were divided into two groups: pubescent (PUB, $n=15$ ) and postpubescent (POSP, $n=19$ ). Torque by angle interaction was established for absolute $[\mathrm{F}(2.649,84.771)=9.066, p<0.05]$ and relative to body mass $[\mathrm{F}(2.704$, $86.533)=4.050, p<0.05]$ isometric torque with the POSP group showing greater values. Muscle volume torque-angle relationship was similar between groups. Absolute, relative to body mass, and relative to muscle volume concentric and eccentric torque-velocity relationship showed a nonsignificant interaction but a significant group effect in favour the POSP group for absolute and concentric torque relative to body mass. Torque-angle and torque-velocity relationship normalized by body mass allometric exponents showed a non-significant interactions and group effects. Muscle thickness $(3.6 \pm 0.6$ vs. $3.8 \pm 0.6 \mathrm{~cm})$, fascicle length $(8.3 \pm 1.4$ vs. $8.9 \pm 1.6 \mathrm{~cm})$ and pennation angle (15.0 \pm 2.3 vs. $14.3 \pm 3.2$ degrees) was similar between PUB and POSP groups, respectively. Maturity status did not show a significant effect on muscle architecture and on isometric and dynamic torques when allometrically normalized.
ARTICLE HISTORY

Accepted 26 February 2019

KEYWORDS

Muscle volume; crosssectional area; pennation angle; fascicle length; allometry

\section{Introduction}

Muscle force typically increases progressively from 8 to 18 years of age (De Ste Croix, Deighan, \& Armstrong, 2003; Nedeljkovic, Mirkov, Kukolj, Ugarkovic, \& Jaric, 2007; Van Praagh \& Dore, 2002). During this period, there is a growth spurt in response to biological maturation, resulting in height, muscle and bone mass increases, and muscle architectural changes, which lead to significant increases in absolute muscle force and torque (Debernard, Robert, Charleux, \& Bensamoun, 2011; De Ste Croix, Armstrong, Welsman, \& Sharpe, 2002; De Ste Croix et al., 2003; Kubo, Kanehisa, Kawakami, \& Fukanaga, 2001; Morse et al., 2008; Nedeljkovic et al., 2007; O'Brien, Reeves, Baltzopoulos, Jones, \& Maganaris, 2010a; Tonson, Ratel, Le Fur, Cozzone, \& Bendahan, 2008). Muscle force is an important variable in sports performance, and its increase is often accompanied by an improvement in soccer-specific abilities like kicks, jumps, sprints, defence, and changes in motion direction and joint stability (Hoff \& Helgerud, 2004). The optimal period (window of opportunity) to improve physical, technical, and physiological capacities has been postulated to occur between the ages of 12 and 16 years, during the course of maturation (Balyi \& Hamilton, 2004).

Proper identification and quantification of the biological maturation effects on muscle force and muscle architecture has been a long-standing problem (Bouchant, Martin, Maffiuletti, \& Ratel, 2011; Herzog et al., 2011) in the selection process and talent identification of young athletes (Cunha et al., 2011; De Ste Croix et al., 2003; Ford et al., 2011; Malina, Eisenmann, Cumming, Ribeiro, \& Aroso, 2004; Nedeljkovic et al., 2007; Ostojic et al., 2014; Philippaerts et al., 2006; Vaeyens et al., 2006; Van Praagh \& Dore, 2002). From a soccer players' talent identification and/or talent development perspective, the interpretation of physical fitness characteristics may be more problematic due to maturity-related differences. Previous findings indicate that independent of chronological age and body size, biological maturation exerts a positive effect on explosive power, strength, speed, aerobic performance, and sport-specific skills (Coelho et al., 2010; Cunha et al., 2011; De Ste Croix et al., 2003; Ford et al., 2011; Malina et al., 2004; Nedeljkovic et al., 2007; Van Praagh \& Dore, 2002). Consequently, biological maturation may have a strong impact on the talent identification and/or talent development process. It is well known that soccer systematically excludes late maturing boys and favours early maturing boys (Figueiredo, Goncalves, Coelho, \& Malina, 2009; Malina et al., 2004; Ostojic et al., 2014). In contrast, recent studies have shown evidence that physical fitness is not affected by biological maturation in soccer players (Cunha et al., 2011, 2016; Figueiredo, Coelho, \& Malina, 2011; Wrigley, Drust, Stratton, Atkinson, \& Gregson, 2014).

Caution should be taken when interpreting studies that examine the effects of biological maturation on sports 
performance, as maturation is often based on chronologic age. In addition, muscle forces are often measured for isometric contractions or few dynamic contractions, while muscle architecture, a morphological parameter that is directly related to biological maturation and maximal force production, is typically ignored (Debernard et al., 2011; De Ste Croix et al., 2003; Kubo et al., 2001; Morse et al., 2008; O'Brien, Reeves, Baltzopoulos, Jones, \& Maganaris, 2009; O'Brien et al., 2010a; O'Brien, Reeves, Baltzopoulos, Jones, \& Maganaris, 2010b). There is a need to understand the effects of biological maturation on muscle architecture, muscle force, the force-length and the force-velocity relations (Barrett \& Harrison, 2002; Borges, Vaz, De La Rocha Freitas, \& Rassier, 2003; Marginson \& Eston, 2001). In addition, methodological procedures, neuromuscular factors, intrinsic muscle factors, and normalization methods may affect the interpretation of muscle force and muscle torque (Barrett \& Harrison, 2002; De Ste Croix et al., 2002, 2003; Jaric, 2002; Nedeljkovic et al., 2007; Tonson et al., 2008).

Although the relation between muscle strength and body size has been frequently studied, the normalization of the measured strength relative to body size has been performed inconsistently (Jaric, 2002, 2003). Dividing muscle force by body mass $(\mathrm{kg})$ is known as the standard normalization (Force. $\mathrm{kg}^{-1}$ ), and has been historically used to control for the body size effect. However, this method has been criticized based on the fact that body mass and muscle force/torque are not linearly related, as muscle force increases at a lower rate and muscle torque at a greater rate than body mass (De Ste Croix et al., 2003; Jaric, 2002; Nevill, Holder, Baxter-Jones, Round, \& Jones, 1998). Therefore, normalization methods that are specific for muscle force and muscle torque are necessary. Allometry has been recommended to adjust the effects of body size over muscle force or torque (Jaric, 2002; Nevill et al., 1998). Allometry is based on the equation $\left(Y=a X^{b}\right)$, where $(a)$ is a constant, and $(b)$ is the scaling exponent corresponding to the body size descriptor. $Y$ is the dependent variable (e.g., force or torque), while $X$ is the body size descriptor (e.g., body mass, muscle volume, cross-sectional area). Proper choice of the allometric exponent $(b)$ allows for appropriate comparisons between subjects of different body size and body composition (Jaric, 2002). Establishing proper normalization procedures allows for distinguishing which factors account for the increases in muscle force/torque in growing adolescent athletes.

The purpose of this study was to determine whether maturity status exerts effects on appropriately normalized isometric and dynamic muscle torques and on muscle architecture of young soccer players.

\section{Methods}

\section{Subjects}

The sample comprised 34 First Division amateur male players from the Brazilian Soccer League. All participants were engaged in formal training ( 5 to 8 training sessions per week, 60-120 minutes per session) and completed one game per week during an 8-month competitive season. All players had at least 2 years of experience as soccer players. The study was approved by the University Research Ethics Board (Project ID\#: 2008082), and was conducted in compliance with the standards set by the Declaration of Helsinki. Participants and their legal guardians were informed of the experimental protocol and the potential risks, and provided written informed consent prior to participation.

\section{Procedures}

Participants were divided into two groups according to their maturity status, including 15 players in the pubescent group (PUB), and 19 in the postpubescent group (POSP). Biological maturation was assessed by a trained healthcare professional using the criteria described by Tanner (Tanner, 1962), based on the genitalia (size and shape of the penis and scrotum) and on pubic hair development. Pubertal status was defined as Tanner stages 2, 3, and 4, and post-pubertal as Tanner stage 5. Height and body mass were determined using a stadiometer and a scale (Urano PS 180A, 0.01-m and 0.1 kg resolution; Rio Grande do Sul, Brazil), respectively. Rectus femoris and vastus intermedius muscle thickness (MT), knee-extensor muscle volume (MV), rectus femoris cross-sectional area (CSA), and vastus lateralis pennation angle (PA) and fascicle length (FL) were measured using ultrasonography, and strength was determined using isokinetic dynamometry.

\section{Muscle architecture}

An ultrasound device with a 6-cm linear array transducer and a sampling frequency of $7.5 \mathrm{MHz}$ (SSD 4000, $51 \mathrm{~Hz}$, ALOKA Inc., Tokyo-Japan) was used to determine architectural variables (MV, MT, CSA, FL and PA) of the knee extensor muscle group. Image J software (version $1.44 \mathrm{x}, \mathrm{NIH}$, USA) was used for all muscle architectural variables analyses.

\section{Muscle volume}

The knee extensor muscle group (vastus lateralis, vastus medialis, vastus intermedius and rectus femoris) muscle volume was determined according to the method reported by Miyatani, Kanehisa, Ito, Kawakami, and Fukunaga (2004). The following equation was used to estimate the knee extensors $\left(\mathrm{Y}_{\mathrm{KE}}\right)$ muscle volume:

$$
Y_{K E}=\left(X_{1} \times 320.6\right)+\left(X_{2} \times 110.9\right)-4437.9
$$

Where: $Y=$ Muscle volume $(\mathrm{ml}) ; X_{1}=$ Muscle thickness of rectus femoris and vastus intermedius $(\mathrm{cm})$; and $X_{2}=\operatorname{Limb}$ length $(\mathrm{cm})$.

For ultrasound measurements, the midpoint on the anterior surface of the thigh (i.e., between the femur's greater trochanter and the joint cavity that includes the femur and the tibial condyles) were carefully identified and marked. Next, the transducer was covered in gel and placed perpendicular to the muscle and bone. Ultrasound measurements were obtained without pressing the probe onto the skin surface. The subcutaneous fat and muscle interface, as well as the 
muscle and bone interface, were identified. These interfaces served as references for measuring MT, defined as the distance between the superficial (rectus femoris) and the deep (vastus intermedius) muscle aponeuroses. Muscle volume was measured using the vastus intermedius and the rectus femoris MT. The intraclass correlation coefficient for the test-retest of MT measurements was $r=0.972$ (Miyatani et al., 2004). The coefficient of repeatability at each measurement site ranged from $1.3 \mathrm{~mm}$ to $1.8 \mathrm{~mm}$. These values were $1.7 \%$ to $5.5 \%$ of the corresponding thickness mean value (Miyatani et al., 2004).

\section{Cross-sectional area}

The ultrasound images used for the determination of the knee extensors' MV were also used to measure the rectus femoris CSA. Rectus femoris CSA was calculated by a planimetric technique (Image J software version 1.44x, NIH, USA) after the inner echogenic line of the rectus femoris was outlined by a movable cursor on a frozen image (Seymour et al., 2009).

\section{Fascicle length and pennation angle}

FL and PA were obtained at rest from the vastus lateralis muscle using ultrasound imaging. The ultrasound probe was positioned longitudinally in the approximate direction of the muscle fibres, at $50 \%$ of the thigh length, with the hip and knee joints fully extended (Maganaris, Baltzopoulos, Ball, \& Sargeant, 2001). When FL exceeded the probe length, FL was estimated using the methodology proposed by Blazevich, Gill, and Zhou (2006). FL was defined as the fascicular distance between the deep and superficial aponeuroses. PA was defined as the angle formed between the muscle fascicle and the deep aponeurosis (Maganaris et al., 2001). FL and PA were determined as the mean of three fascicles obtained on each ultrasound image. FL (in $\mathrm{cm}$ ) was normalized by the thigh length $\left(\mathrm{FL}_{n}\right)$ to allow for between-subjects comparison.

\section{Isokinetic dynamometry}

An isokinetic dynamometer (Biodex Medical System, Shirley - NY, USA) was used to determine the torqueangle and torque-velocity relations. After a 5-minute warm up on a cycle ergometer, athletes were sat on the dynamometer chair, with the lateral femoral epicondyle aligned with the dynamometer's axis of rotation. The hip and knee joints were kept at an angle of $90^{\circ}\left(0^{\circ}=\right.$ full extension). The trunk and thigh were stabilized with belts, and the knee maximal joint range of motion was determined. Familiarization trials were performed by executing one maximal voluntary contraction at knee angles of $30^{\circ}, 60^{\circ}$, and $90^{\circ}$, and three concentric-eccentric contractions at angular velocities of $60^{\circ} \cdot \mathrm{s}^{-1}, 120^{\circ} \cdot \mathrm{s}^{-1}$ and $240^{\circ} \cdot \mathrm{s}^{-1}$.

For the torque-angle relation, subjects performed one maximal voluntary contraction at six different joint angles $\left(30^{\circ}, 45^{\circ}\right.$, $60^{\circ}, 75^{\circ}, 90^{\circ}$ and $105^{\circ} ; 0^{\circ}=$ full knee extension) to assess isometric peak torque. Isometric peak torque was defined as the highest torque achieved during isometric contractions for each joint angle. A 1.5 min interval was observed between consecutive contractions to avoid fatigue.
For the torque-velocity relation, athletes performed three maximal concentric-eccentric knee extensor contractions at six different angular velocities $\left(30^{\circ} \cdot \mathrm{s}^{-1}, 60^{\circ} \cdot \mathrm{s}^{-1}, 90^{\circ} \cdot \mathrm{s}^{-1}, 120^{\circ} \cdot \mathrm{s}^{-1}\right.$, $180^{\circ} \cdot \mathrm{s}^{-1}$ and $240^{\circ} \cdot \mathrm{s}^{-1}$ ) to access concentric and eccentric peak torque. A 2.0 min interval was observed between consecutive velocities to avoid fatigue. Peak concentric and eccentric torques were defined as the highest torques achieved among the three dynamic contractions in concentric and eccentric actions, respectively. All athletes received verbal encouragement to reach maximal effort during the maximal effort tests, as well as visual feedback of their performance.

Torque signals were collected using a Windaq software (sampling frequency $=2000 \mathrm{~Hz}$ per channel) and stored on a personal computer for further analysis in MATLAB (MATLAB version 7.3.0.267, MathWorks, Inc., Natick, MA, USA).

\section{Statistical analysis}

Normality of the data distribution was evaluated using the Shapiro-Wilk test, and homoscedasticity of the variables was assessed using Levene's test. The mean and standard deviation values were used for descriptive purposes. Physical and muscle architecture between-groups comparisons were performed using independent t-tests. Effect size (ES) Cohen's $d$ was calculated for these comparisons (Hopkins, 2000; Hopkins, Marshall, Batterham, \& Hanin, 2009) and interpreted as follows (Hopkins et al., 2009): $<0.20$ (trivial), 0.20 to 0.59 (small), 0.60 to 1.19 (moderate), 1.20 to 1.99 (large), 2.0 to 3.9 (very large), > 4.0 (nearly perfect).

Pearson's analysis of correlation was used to investigate correlations among muscle architecture, torque, and body size descriptors. The magnitude of correlations was interpreted as follows: trivial $(r<0.1)$, small $(0.1<r<0.3)$, moderate $(0.3<r<0.5)$, large $(0.5<r<0.7)$, very large $(0.7<r<0.9)$, and nearly perfect $(r>0.9)$ (Hopkins et al., 2009).

Allometric exponents were calculated using natural logarithms (In) of absolute torque (Nm) and In of body descriptors, such as body mass $(\mathrm{Kg})$ and $\mathrm{MV}(\mathrm{ml})$. The allometric exponents were calculated using the initial allometric model: $Y=a \times X^{b} \times \varepsilon$. Values of $(a)$ and $(b)$ were obtained from linear regressions of the logarithmic regression transformations in the form of: $\ln Y=\ln a+b \ln X+\ln \varepsilon$. Where: $(a)$ is a scale constant and $(b)$ is the scaling exponent corresponding to a body size descriptor. Ycorresponds to the value of the dependent variables (In isometric torque, In concentric torque, and $I n$ eccentric torque) and $X$ corresponds to the body size descriptors ( $I n$ body mass and In MV). The homogeneity of the allometric exponents was verified using ANCOVA with the inclusion of an interaction term (group $\times$ In body size descriptors). The statistical assumptions used to estimate the exponents were investigated using methods previously described in the literature (Cunha et al., 2011; Jaric, 2002; Nevill, Ramsbottom, \& Williams, 1992; Valente-Dos-Santos et al., 2015, 2013; Zoeller et al., 2008). For an allometric model to be deemed appropriate, there should be no significant correlation between the allometrically scaled torque $\left(\mathrm{Nm}_{\mathrm{kg}} \mathrm{k}^{-\mathrm{b}}\right.$ or $\mathrm{Nm} \cdot \mathrm{ml}^{-\mathrm{b}}$ ) and the body descriptor (body mass or muscle volume). Correlation coefficients that do not approach zero, 
regardless of whether they are statistically significant, would suggest that the proportional allometric model was not completely successful in rendering isokinetic torque outputs independent of body size (Carvalho et al., 2012; Nevill et al., 1992). In addition, the homogeneity of regression slopes between PUB and POSP groups could indicate that the allometric model was successful in scaling torque independent of maturational group and body size descriptor (Cunha et al., 2011, 2016; Zoeller et al., 2008).

Two-way ANOVAs for repeated measures were used to analyse within-group and between-group main effects (isometric, concentric, and eccentric torque) as well as groupangle and group-velocity interactions. Bonferroni post-hoc testing was used to establish the location of significant differences between groups. The assumption of sphericity was confirmed by the Mauchly test. Where sphericity was violated, a Greenhouse-Geiser adjustment was implemented. The within-group comparisons are not shown. Partial eta-squared $\left(\eta^{2}\right)$ was calculated as a measure of ES. Values of $0.01,0.06$ and above 0.15 were considered as small, medium and large, respectively (Cohen, 1988).

Statistical analyses were conducted using SPSS (version 19.0, SPSS, Inc., IBM Company; NY, USA) and GraphPad Prism (version 5.03, GraphPad Software, La Jolla, CA) softwares. The level of significance was set at $p<0.05$.

\section{Results}

As expected, the POSP group athletes were older, and had greater body mass, height, thigh length and MV compared to the PUB group athletes (Table 1). There were no betweengroup differences for the remaining muscle architectural variables $\left(F L, F_{n}, P A\right)$ and training time.

The correlations among isometric, concentric, and eccentric torque with body size descriptors were as follows: body mass (0.589<r<0.838; $p<0.05)$, MV (0.362< $r<0.610 ; p<0.05)$. Following normalization of the isometric and dynamic torques by body mass $\left(\mathrm{Nm}_{\mathrm{kg}}{ }^{-1}\right)$ and $\mathrm{MV}\left(\mathrm{Nm} \cdot \mathrm{ml}^{-1}\right)$, they remained significantly correlated with body mass $(0.410<r<0.450 ; p<$ $0.05)$, and MV $(-0.424<r<-0.593, p<0.05)$. The allometric exponents calculated for body mass and MV are described in Table 2. MV did not provide a significant allometric exponent to dynamic torque $(p>0.05)$, and the assumption of homogeneity among the exponents was broken. Body mass provided significant allometric exponents to isometric and dynamic torques (Cunha et al., 2011; Jaric, 2002; Nevill et al., 1992; Zoeller et al., 2008).

The absolute torque-angle $(\mathrm{Nm})$ relationship showed a significant torque by angle interaction $[F(2.649,84.771)=$ 9.066, $p<0.05$, ES $=0.221]$, and angle and group main effects $(p<0.05)$ with the POSP group showing greater absolute isometric torque values compared to the PUB group (Figure 1(a)). The torque-angle relative to body mass $\left(\mathrm{Nm}_{\mathrm{kg}}{ }^{-1}\right)$ relationship showed a significant torque by angle interaction $[F(2.704,86.533)=4.050, p<0.05$, $\mathrm{ES}=0.112]$, and angle and group main effects $(p<0.05)$ with the POSP group showing greater isometric torque relative to body mass values compared to the PUB group (Figure 1(b)). The muscle volume torque-angle $\left(\mathrm{Nm} \cdot \mathrm{ml}^{-1}\right)$
Table 1. Participant's characteristics according to their maturity status.

\begin{tabular}{lcccl}
\hline Variable & PUB & POSP & ES & ES $_{\mathrm{q}}$ \\
\hline Age (years) & $14.5 \pm 0.8$ & $16.6 \pm 1.2^{*}$ & 2.059 & Very large \\
Body mass (kg) & $64.2 \pm 7.8$ & $76.6 \pm 7.0^{*}$ & 1.673 & Large \\
Height $(\mathrm{m})$ & $1.73 \pm 5.3$ & $1.82 \pm 6.3^{*}$ & 0.015 & Trivial \\
Training time (years) & $4.6 \pm 2.3$ & $4.2 \pm 2.3$ & 0.173 & Trivial \\
Limb length (cm) & $43.4 \pm 1.5$ & $45.4 \pm 2.0^{*}$ & 1.131 & Moderate \\
Muscle thickness (cm) & $3.6 \pm 0.6$ & $3.8 \pm 0.6$ & 0.333 & Small \\
Muscle volume (ml) & $1526 \pm 307$ & $1814 \pm 410^{*}$ & 0.793 & Moderate \\
CSA (cm ${ }^{2}$ ) & $9.8 \pm 1.9$ & $10.3 \pm 2.0$ & 0.256 & Small \\
FL (cm) & $8.3 \pm 1.4$ & $8.9 \pm 1.6$ & 0.332 & Small \\
FL $(\mathrm{cm})$ & $0.19 \pm 0.03$ & $0.20 \pm 0.03$ & 0.333 & Small \\
PA (degrees) & $15.0 \pm 2.3$ & $14.3 \pm 3.2$ & 0.251 & Small \\
\hline
\end{tabular}

Data expressed as the mean and standard deviation (mean $\pm \mathrm{SD}$ ), where $*$ = significantly different from pubescent group; $\mathrm{FL}=$ vastus lateralis fascicle length; $F L_{n}=$ vastus lateralis normalized fascicle length; $P A=$ vastus lateralis pennation angle; $C S A=$ rectus femoris cross-section area; $P U B=$ pubescent group; $\mathrm{POSP}=$ postpubescent group; $\mathrm{ES}=$ Cohen's d effect size; $\mathrm{ES}_{\mathrm{q}}=$ qualitative effect size. Significance $(p<0.05)$.

relationship showed a non-significant torque by angle interaction $[\mathrm{F}(2.682,80.455)=2.812, p>0.05, \mathrm{ES}=0.086]$ and group effect $(p>0.05)$, resulting in similar values of isometric torque relative to muscle volume between groups, but a significant angle effect was observed $(p<0.05)$ (Figure 1(c)).

The absolute eccentric torque-velocity $(\mathrm{Nm})$ relationship showed non-significant torque by velocity interaction $[\mathrm{F}(5$, $160)=1.567, p>0.05, \mathrm{ES}=0.047]$, but showed significant velocity and group main effects $(p<0.05)$, with the POSP athletes showing greater absolute eccentric torque values compared to the PUB group (Figure 2(a)). The absolute concentric torque-velocity $(\mathrm{Nm})$ relationship showed a nonsignificant torque by velocity interaction $[F(3.529,112.922)=$ $0.510, p>0.05, \mathrm{ES}=0.016]$, but showed significant velocity and group main effects $(p<0.05)$ with the POSP athletes achieving greater values of absolute concentric torque compared to the PUB group (Figure 2(b)). The eccentric torquevelocity relative to body mass $\left(\mathrm{Nm}_{\mathrm{kg}} \mathrm{k}^{-1}\right)$ relationship showed a non-significant torque by velocity interaction [F $(3.782,121.014)=1.282, p>0.05$, ES $=0.039$ ], and group effect $(p>0.05)$, but a significant velocity effect $(p<0.05)$ (Figure 2(c)). The concentric torque-velocity relative to body mass $\left(\mathrm{Nm}_{\mathrm{kg}} \mathrm{k}^{-1}\right)$ relationship showed a non-significant torque by velocity interaction $[\mathrm{F}(3.620,115.853)=0.499, p>$ $0.05, \mathrm{ES}=0.015]$, but significant velocity and group main effects $(p<0.05)$, with the POSP athletes showing greater values compared to the PUB athletes (Figure 2(d)). The muscle volume eccentric torque-velocity $\left(\mathrm{Nm} \cdot \mathrm{ml}^{-1}\right.$ ) relationship showed non-significant torque by velocity interaction $[F(3.731,119.378)=1.240, p>0.05, E S=0.037]$ and group effect $(p>0.05)$, but a significant velocity effect was established $(p<0.05)$ (Figure 2(e)). The muscle volume concentric torque-velocity $\left(\mathrm{Nm} \cdot \mathrm{ml}^{-1}\right)$ relationship showed a nonsignificant torque by velocity interaction $[F(3.189$, $102.060)=0.412, p>0.05, \mathrm{ES}=0.013]$, and group effect $(p>0.05)$, but a significant velocity effect was observed $(p<$ 0.05 ) (Figure 2(f)).

There were no significant differences between the POSP and PUB groups for the torque-angle and torque-velocity relations when torque values were normalized using specific allometric exponents relative to body mass $\mathrm{Nm}_{\mathrm{kg}}{ }^{-\mathrm{b}}$ (Tables $3-5$ ). 
Table 2. Allometric exponents calculated for isometric, concentric, and eccentric knee extensor torques relative to muscle volume (MV) and body mass (BM).

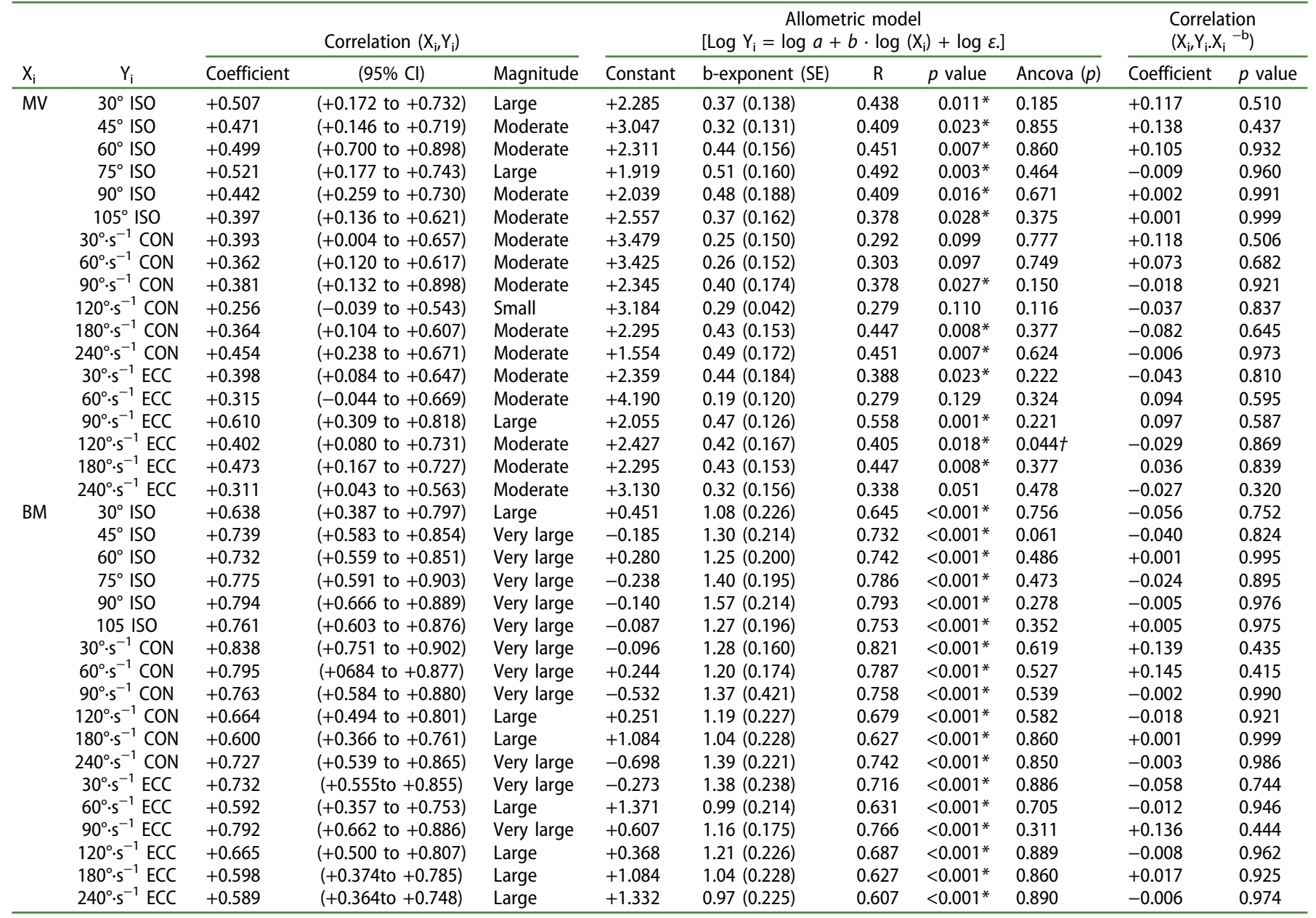

Equation used for the calculation of the scaling allometric exponents: $\ln Y=\ln a+b \ln X+\ln \varepsilon$, where $Y$ corresponds to dependent variables as isometric (ISO), concentric (CON), and eccentric (ECC) torque ( $\mathrm{Nm}$ ) transformed to natural logarithms, and $X$ corresponds to body size descriptor, such as body mass (kg) and muscle volume $(\mathrm{ml})$. The exponent's homogeneity was verified by ANCOVA, where $\dagger$ means that the homogeneity of the regression slopes has been broken thereby indicating that the allometric model was not successful in scaling torque independent of maturational group and body size $(p<0.05) ;{ }^{*}=b$-coefficient statistically significant $(p<0.05) ; b=$ scaling allometric exponents relative to body size descriptors; $95 \% \mathrm{Cl}=95 \%$ confidence interval of $b$; $B M=$ body mass; $\mathrm{MV}=$ muscle volume.

\section{Discussion}

To the best of our knowledge, this is the first study in which the effects of maturity status on vastus lateralis muscle architecture, knee extensor torque-angle and torque-velocity relations, normalized by allometry, were verified in young soccer players. Our main findings were that: (1) maturity status did not show a significant effect on isometric, concentric or eccentric torques after allometric normalization; (2) maturity status did not show a significant effect on vastus lateralis muscle architecture (PA, CSA, FL, FLn, MT), except for MV; (3) allometric exponents relative to body mass $\left(\mathrm{Nm}_{\mathrm{kg}} \mathrm{kg}^{-\mathrm{b}}\right)$ were considered the best way to normalize isometric and dynamic torques in comparison to the standard normalization to body mass $\left(\mathrm{Nm}^{\mathrm{kg}}{ }^{-1}\right)$, to the anatomical cross-sectional area $(\mathrm{Nm}$. $\left.\mathrm{CSA}^{-1}\right)$, and to $\mathrm{MV}\left(\mathrm{Nm} \cdot \mathrm{MV}^{-1}\right.$ and $\left.\mathrm{Nm} \cdot \mathrm{MV}^{-\mathrm{b}}\right)$, respectively.

Absolute knee extensor torques $(\mathrm{Nm})$ have been shown to increase progressively by about 300\% for boys and young soccer players between 8-21 years of age (De Ste Croix et al., 2003; Nedeljkovic et al., 2007; Van Praagh \& Dore, 2002), with an exponential increase during the maturational process (De Ste Croix et al., 2003; Forbes et al., 2009a; Forbes, Sutcliffe,
Lovell, McNaughton, \& Siegler, 2009b; Holm, Steen, \& Olstad, 2005). A similar behaviour is observed when torque is normalized by body mass, with normalized strength increases varying between 1.5 to $3.1 \mathrm{Nm}^{\mathrm{kg}}{ }^{-1}$. Our results about absolute and normalized peak torque are in agreement with previous studies considering chronological age, maturity status, sport, and contraction type (Forbes et al., 2009a, 2009b; Holm et al., 2005).

However, the typical normalization procedures used ( $N$. $\mathrm{kg}^{-1}$ or $\mathrm{Nm} \cdot \mathrm{kg}^{-1}$ ) have limitations. The main limitation is that knee extensor force and torque do not scale linearly with body mass, as force increases at a smaller rate and torque at a larger rate than body mass (Jaric, 2002; Nevill et al., 1998). Therefore, normalization to body mass $\left(\mathrm{kg}^{-1}\right)$ does not capture well the increases in knee extensor force and torque with growth in young soccer players (Bouchant et al., 2011; De Ste Croix et al., 2003; Herzog et al., 2011). Our results show that knee extensor torques remain significantly correlated with body mass after normalization to body mass, because knee extensor torques increase at a greater rate than body mass, with a mean allometric exponent of $b=1.2$ with a range of $0.97<b<1.57$ for isometric and dynamic contractions. 

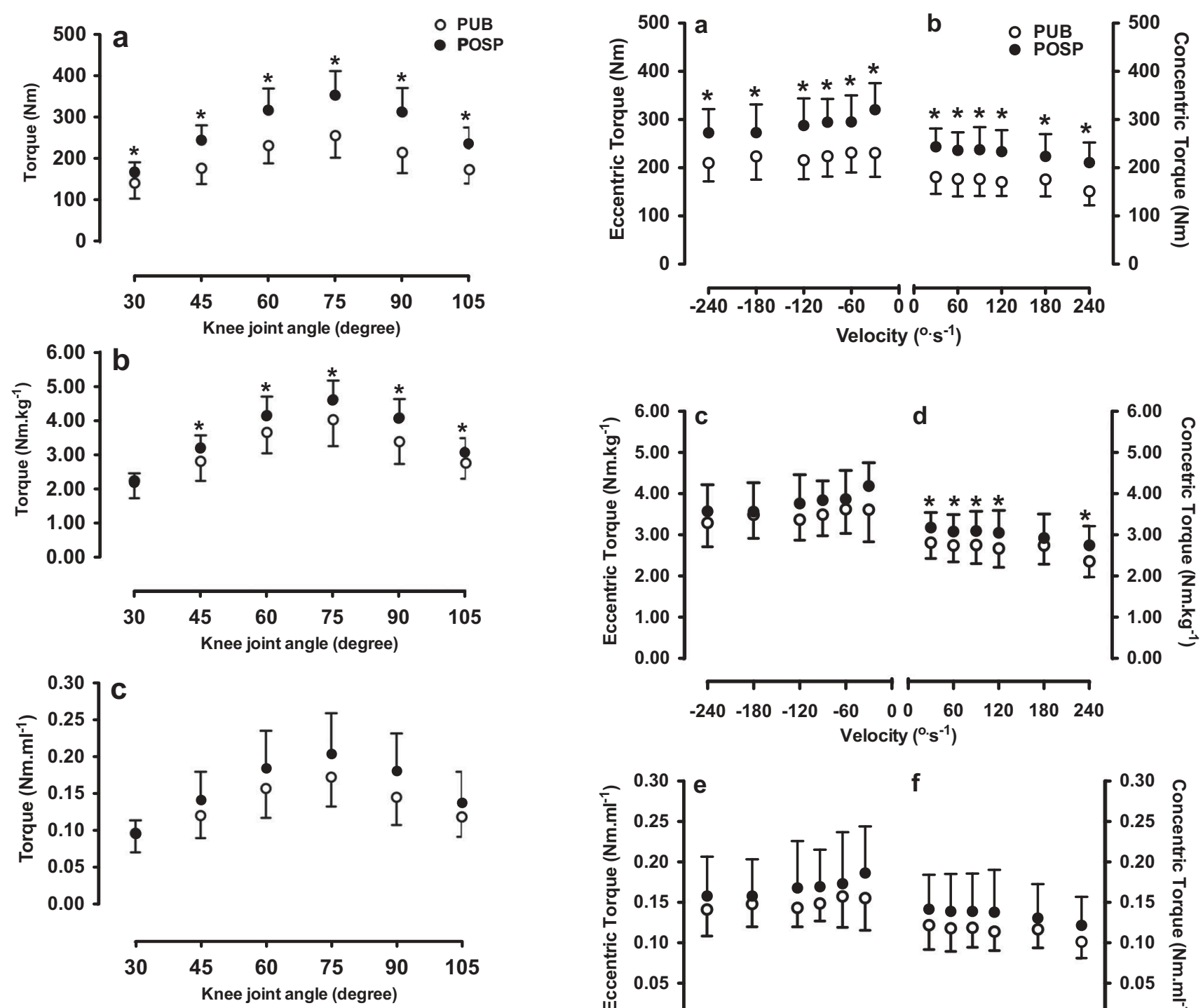

Figure 1. Torque-angle relationship for pubescent (PUB) and postpubescent (POSP) soccer players expressed in (a) absolute; (b) relative to body mass; and (c) relative to muscle volume isometric torque values * Indicates significant difference between groups $(p<0.05)$.

Although it is obvious that children produce less absolute force and torque than adults, it is not obvious how these strength differences change when force and torque are normalized by dimensional variables related to growth and maturation (Bouchant et al., 2011; De Ste Croix et al., 2003; Herzog et al., 2011; Tonson et al., 2008). However, understanding and isolating the effects of training, growth, maturation, and chronological age on muscle force and torque is complex. Several factors may explain the variations in muscle force and torque in children and adolescents. These factors are neuromuscular (voluntary activation of agonist muscles, coactivation

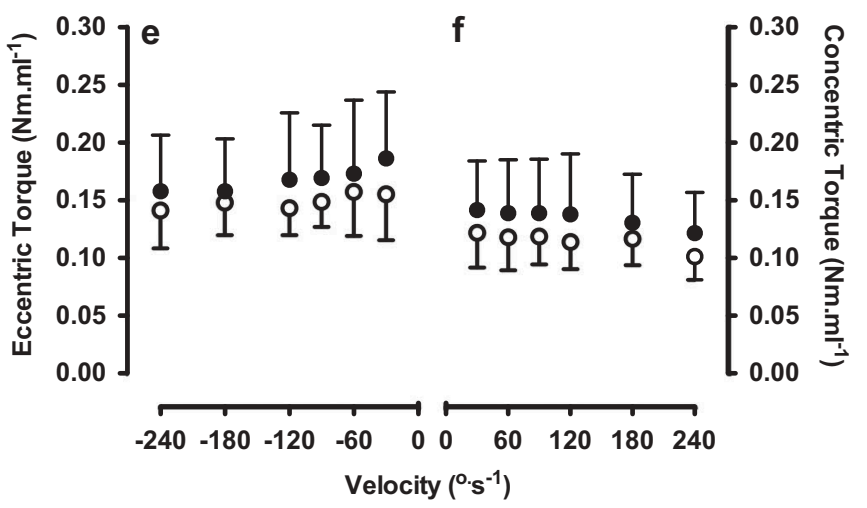

Figure 2. Torque-velocity relationship for pubescent (PUB) and postpubescent (POSP) soccer players expressed in (a) absolute eccentric torque; (b) absolute concentric torque; (c) relative to body mass eccentric torque; (d) relative to body mass concentric torque; (e) relative to muscle volume eccentric torque; and ( $f$ ) relative to muscle volume concentric torque values. ${ }^{*}$ Indicates significant difference between groups $(p<0.05)$.

of antagonist muscles and muscle coordination), biomechanical (lever arm and joint moment), muscular (tendon stiffness, fibre type, enzymatic activity, muscular glycogen, force-time history of muscle contraction, connective tissue, myofibrillar density and non-contractile material infiltration - e.g. fat infiltration), methodological (contraction type, stability and gravity

Table 3. Isometric torque-angle relationship normalized by allometric exponents relative to body mass of soccer players.

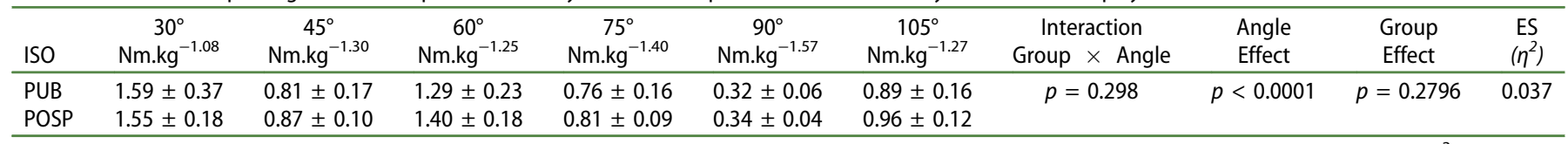

Data expressed as the mean and standard deviation (mean $\pm S D)$. PUB = pubescent group; POSP = postpubescent group; ES = partial eta-squared $\left(\eta^{2}\right)$ effect size; ISO = isometric torque. Significance $(p<0.05)$. 
Table 4. Concentric torque-velocity relationship normalized by allometric exponents relative to body mass of soccer players.

\begin{tabular}{|c|c|c|c|c|c|c|c|c|c|c|}
\hline & $30^{\circ} \cdot \mathrm{s}^{-1}$ & $60^{\circ} \cdot \mathrm{s}^{-1}$ & $90^{\circ} \cdot \mathrm{s}^{-1}$ & $120^{\circ} \cdot \mathrm{s}^{-1}$ & $180^{\circ} \cdot \mathrm{s}^{-1}$ & $240^{\circ} \cdot \mathrm{s}^{-1}$ & $\begin{array}{l}\text { Interaction } \\
\text {. }\end{array}$ & Velocity & Group & ES \\
\hline & & & & & & & & & & \\
\hline $\begin{array}{l}\text { PUB } \\
\text { POSP }\end{array}$ & $\begin{array}{l}0.88 \pm 0.12 \\
0.94 \pm 0.11\end{array}$ & $\begin{array}{l}1.19 \pm 0.17 \\
1.29 \pm 0.17\end{array}$ & $\begin{array}{l}0.59 \pm 0.10 \\
0.62 \pm 0.09\end{array}$ & $\begin{array}{l}1.21 \pm 0.22 \\
1.33 \pm 0.24\end{array}$ & $\begin{array}{l}2.32 \pm 0.39 \\
2.46 \pm 0.49\end{array}$ & $\begin{array}{l}0.47 \pm 0.08 \\
0.51 \pm 0.09\end{array}$ & $p=0.573$ & $<0.0001$ & $p=0.1350$ & 0.016 \\
\hline
\end{tabular}

Data expressed as the mean and standard deviation (mean $\pm S D) . P U B=$ pubescent group; POSP = postpubescent group; ES = partial eta-squared $\left(\eta^{2}\right)$ effect size; $\mathrm{CON}=$ concentric torque. Significance $(\mathrm{p}<0.05)$.

Table 5. Eccentric torque-velocity relationship normalized by allometric exponents relative to body mass of soccer players.

\begin{tabular}{|c|c|c|c|c|c|c|c|c|c|c|}
\hline ECC & $\begin{array}{c}30^{\circ} \cdot \mathrm{s}^{-1} \\
\mathrm{Nm} \cdot \mathrm{kg}^{-1.38}\end{array}$ & $\begin{array}{c}60^{\circ} \cdot \mathrm{s}^{-1} \\
\mathrm{Nm} \cdot \mathrm{kg}^{-0.99}\end{array}$ & $\begin{array}{c}90^{\circ} \cdot \mathrm{s}^{-1} \\
\mathrm{Nm} \cdot \mathrm{kg}^{-1.16}\end{array}$ & $\begin{array}{c}120^{\circ} \cdot \mathrm{s}^{-1} \\
\mathrm{Nm} \cdot \mathrm{kg}^{-1.21}\end{array}$ & $\begin{array}{c}180^{\circ} \cdot \mathrm{s}^{-1} \\
\mathrm{Nm} \cdot \mathrm{kg}^{-1.04}\end{array}$ & $\begin{array}{c}240^{\circ} \cdot \mathrm{s}^{-1} \\
\mathrm{Nm} \cdot \mathrm{kg}^{-0.97}\end{array}$ & $\begin{array}{c}\text { Interaction } \\
\text { Group } \times \text { Velocity }\end{array}$ & $\begin{array}{l}\text { Velocity } \\
\text { Effect }\end{array}$ & $\begin{array}{l}\text { Group } \\
\text { Effect }\end{array}$ & $\begin{array}{l}\text { ES } \\
\left(\eta^{2}\right)\end{array}$ \\
\hline PUB & $0.74 \pm 0.18$ & $3.77 \pm 0.61$ & $1.79 \pm 0.26$ & $1.41 \pm 0.21$ & $2.95 \pm 0.49$ & $3.73 \pm 0.65$ & $p=0.450$ & $p<0.0001$ & $p=0.1974$ & 0.027 \\
\hline POSP & $0.80 \pm 0.11$ & $4.04 \pm 0.72$ & $1.92 \pm 0.23$ & $1.51 \pm 0.28$ & $3.00 \pm 0.59$ & $4.07 \pm 0.73$ & & & & \\
\hline
\end{tabular}

Data expressed as the mean and standard deviation (mean \pm SD). PUB = pubescent group; POSP = postpubescent group; $E S=$ partial eta-squared $\left(\eta^{2}\right)$ effect size; $E C C=$ eccentric torque. Significance $(p<0.05)$.

correction), dimensional (body mass, body mass index, free fat mass, CSA, physiological cross-sectional area - PCSA, FL and $M V)$, structural (PA, FL, MT, CSA, PCSA and MV), and the biological maturation process (Barrett \& Harrison, 2002; Bouchant et al., 2011; De Ste Croix et al., 2002, 2003; Herzog et al., 2011; Jaric, 2002; O'Brien et al., 2009, 2010a; Radnor et al., 2018; Tonson et al., 2008; Van Praagh \& Dore, 2002).

Biological maturation is a critical variable when analysing strength development in children, adolescents and young athletes, as there is an exponential increase in height, body mass, fat free mass, CSA and MV during maturation (Boisseau \& Delamarche, 2000; De Ste Croix et al., 2003; Van Praagh \& Dore, 2002), and increases in testosterone, IGF-I production (Boisseau \& Delamarche, 2000; De Ste Croix et al., 2003; Van Praagh \& Dore, 2002), myelinisation, nervous system development (Boisseau \& Delamarche, 2000; De Ste Croix et al., 2003) and changes in muscle architecture (Debernard et al., 2011; Kubo et al., 2001; Morse et al., 2008; O'Brien et al., 2009, 2010a, 2010b). Our results confirm the obvious changes in body dimensions and MV, but do not support the expected changes in muscle architecture.

Similar to previous studies (De Ste Croix et al., 2002; Fukunaga et al., 2014; Holm et al., 2005; Morse et al., 2008; O'Brien et al., 2009, 2010a; Tonson et al., 2008), maturity status did not show a significant effect on knee extensor torque. Morse et al. (2008) did not find differences between early pubescent children and adults when the gastrocnemius lateralis torque was normalized to CSA. Fukunaga et al. (2014) showed that isometric maximal torques of knee extensor and ankle plantar flexor muscles were not different between prepubertal and pubertal groups when normalized to MV. O'Brien et al. (2009) observed significant differences in absolute torques among men, women, and prepubescent boys and girls. However, when torques were normalized by MV, the betweengroup differences disappeared. Similar results were observed for pre-pubescent children and adults when torques were normalized to PCSA, showing that the torque increase that occurred during biological maturation was not due to the specific tension (force/PCSA) (O'Brien et al., 2010a). This is in agreement with our results.

Studies aimed at determining the effects of biological maturation on knee extensor strength in young soccer players are rare. Holm et al. (2005) conducted an 11-year longitudinal study aimed at evaluating the development of isokinetic knee extensor torque before, during and after the maturational process. Pubescent subjects showed greater knee extensor and flexor torques than pre-pubescent subjects, but smaller than post-pubescent subjects for absolute torque and for torques normalized by body mass. They concluded that there was a biological maturation effect, with an exponential increase between 12 and 17 years (Holm et al., 2005).

Due to the insufficiency of standard normalization to adequately predict strength of subjects of different chronological ages, different body composition, different maturational status, and different performance levels, allometric scaling has been considered an emergent method that successfully accommodates the nonlinear relationship between body size descriptors and muscle force and torque (Jaric, 2002; Nevill et al., 1998). When the data of the present study were normalized by allometry, no significant differences between maturational groups were observed in the six angles and the 12 different velocities of muscle contraction tested, in contrast to comparisons made with the absolute values $(\mathrm{Nm})$ and the values normalized to body mass $\left(\mathrm{Nm}_{\mathrm{kg}}{ }^{-1}\right)$.

Our results demonstrate the importance of establishing the best variable for torque normalization. Similar results were shown by De Ste Croix et al. (2002), who concluded that biological maturation did not influence knee flexor and extensor isokinetic torques in boys and girls when height and body mass were controlled by allometry. In the same way, biological maturation has been suggested to have little influence on the strength-size relationship in the lower extremity muscles around puberty (Fukunaga et al., 2014).

Muscle architectural variables have been considered determinants of muscle function. Muscles with a large CSA, MV, and PA are built for great force production, while muscles with long FL are built for high shortening velocity and large excursion (Blazevich, 2006). Muscle architectural variables have been shown to adapt in response to chronic training, detraining, reduced use, immobilization, injury, growth, biological maturation and aging (Blazevich, 2006). Specifically, studies have shown that, through growth and biological maturation, increases occur in PA, FL, MT and CSA (Debernard et al., 2011; Fukunaga et al., 2014; Kubo et al., 2001; Morse et al., 2008; O'Brien et al., 2009, 2010a, 2010b; Tonson et al., 2008). In contrast, our results do not demonstrate a significant effect 
of biological maturation on muscle architecture variables, except for MV. Children usually have shorter FL in the vastus lateralis muscle $(6.2-7.6 \mathrm{~cm})$ than adolescents $(8.0 \mathrm{~cm})$ and adults $(6.9-9.4 \mathrm{~cm})$, similar values of PA $\left(15.8-16.2^{\circ}\right)$ as adolescents $\left(16.6^{\circ}\right)$ and adults $\left(13.2-21.0^{\circ}\right)$, but smaller values than athletes $\left(18-23^{\circ}\right)$ (Kanehisa, Muraoka, Kawakami, \& Fukunaga, 2003; Kearns, Isokawa, \& Abe, 2001; Kubo et al., 2001; O'Brien et al., 2010a, 2010b). FL, $\mathrm{FL}_{n}$ and PA in our study were similar for pubescent and postpubescent soccer athletes. One explanation for these results might be that increases in FL typically occur during the pre-pubescent period, whereas substantial increases in muscle CSA typically occur during the pubescent period (Morse et al., 2008).

Muscle architectural parameters influence the force-length (torque-angle) and force-velocity (torque-velocity) properties of skeletal muscles. In soccer, the force-length and forcevelocity relations are determinants for the ability to kick a ball hard and pass it accurately, for sprinting and jumping, and perturbations of these properties may lead to muscular imbalance and injury (Hoff \& Helgerud, 2004). Studies aimed at comparing torque-angle and the torque-velocity properties between children and adults are rare, and virtually nonexistent for athletic populations (Barrett \& Harrison, 2002; Borges et al., 2003; Marginson \& Eston, 2001). Marginson and Eston (2001) compared force-length relations of the knee extensor muscles between children and adults, and reported that this relation was shifted to the right (i.e. longer muscle lengths or more flexed knee angles) for the children compared to the adults. This result was justified by the smaller passive muscle stiffness in the children, and the authors concluded that the force-length relation is affected by chronological age. However, this study did not use any normalization method to adjust for body size differences between the children and the adults. Barret and Harrisson (2002) examined the torquevelocity relation in children and adults. They found differences in the absolute torque-velocity relation, and these differences remained even after torques were normalized by CSA and angular velocity by limb length. However, when torques were normalized by MV, the differences disappeared, suggesting that the torque differences between children and adults are due to the muscle size, and not due to changes associated with maturation. Our results partially support this idea, as we observed significant differences between the PUB and POSP athletes for the absolute torque-angle and torque-velocity relations, and for these relations when normalized by body mass $\left(\mathrm{Nm}_{\mathrm{kg}} \mathrm{k}^{-1}\right.$ ), but not when torques were normalized by MV. Nevertheless, we found the normalization by MV inadequate for our data because isometric and dynamics torques relative to $\mathrm{MV}\left(\mathrm{Nm} \cdot \mathrm{ml}^{-1}\right)$ remained significantly correlated with $\mathrm{MV}$, it was unable to provide a significant allometric exponent for dynamic torque, and the assumption of homogeneity among the exponents was broken (Table 2).

The effect of maturity status on force and torque observed in past studies could be partially explained by applying different methods to assess force/torque, biological maturation, and inappropriate data normalization. A criticism for studies that do not normalize force/torque outcomes is that the methodological approach may not guarantee a fair comparison among athletes at different stages of maturation or with different body sizes, resulting in selection bias. Thus, the discrepancy between these results could be due to a phenomenon known as the scaling denominator (Bouchant et al., 2011; De Ste Croix et al., 2003; Herzog et al., 2011).

A possible limitation of the present study is that, for the torque-angle relation, participants performed only one maximal voluntary contraction for each of the six different joint angles tested. As a suggestion, future studies could include a prepubescent group of athletes and groups of non-athletes for the varying maturational stages in order to determine the effects of soccer training on the physical development. In addition, measuring MV and physiological CSA through magnetic resonance imaging rather than ultrasound could improve the accuracy and reliability of these measures, resulting in an improved relation among muscle architectural parameters and muscular torques. Finally, measuring muscle activation of agonistic and antagonistic muscle groups could allow to distinguish if changes in muscle force are caused by intrinsic muscular changes or by changes in neural activation.

To conclude, maturity status did not show a significant effect on isometric and dynamic torques (concentric and eccentric) when they were normalized by allometric exponents relative to body mass. The progressive force and torque increases, generally attributed to biological maturation during the transition from child to adulthood, seem to be caused by the effect known as scaling denominator. Muscle architectural variables were not influenced by biological maturation, except for MV.

\section{Acknowledgments}

The authors MAV and ARO were supported by a scholarship from CNPq (Brazilian Council of Science and Technology) and GSC and GTL by a scholarship from CAPES (Coordination for the Improvement of Higher Level - or Education - Personnel). The authors acknowledge the great effort by the players in the present study. We sincerely thank Dr. Fernando de Aguiar Lemos by his technical support during data analyses.

\section{Disclosure statement}

No potential conflict of interest was reported by the authors.

\section{ORCID}

Giovani dos Santos Cunha (iD) http://orcid.org/0000-0003-0241-9633

\section{References}

Balyi, I., \& Hamilton, A. (2004). Long-term athlete development: Trainability in childhood and adolescence-Windows of opportunity, optimal trainability. Victoria, BC: National Coaching Institute British Columbia and Advanced Training and Performance Ltd.

Barrett, U., \& Harrison, D. (2002). Comparing muscle function of children and adults: Effects of scaling for muscle size. Pediatric Exercise Science, 14(4), 369-376.

Blazevich, A. J. (2006). Effects of physical training and detraining, immobilisation, growth and aging on human fascicle geometry. Sports Medicine, 36(12), 1003-1017.

Blazevich, A. J., Gill, N. D., \& Zhou, S. (2006). Intra- and intermuscular variation in human quadriceps femoris architecture assessed in vivo. Journal of Anatomy, 209(3), 289-310. 
Boisseau, N., \& Delamarche, P. (2000). Metabolic and hormonal responses to exercise in children and adolescents. Sports Medicine, 30(6), 405-422.

Borges, G. M., Vaz, M. A., De La Rocha Freitas, C., \& Rassier, D. E. (2003). The torque-velocity relation of elite soccer players. The Journal of Sports Medicine and Physical Fitness, 43(3), 261-266.

Bouchant, A., Martin, V., Maffiuletti, N. A., \& Ratel, S. (2011). Can muscle size fully account for strength differences between children and adults? Journal of Applied Physiology, 110(6), 1748-1749.

Carvalho, H. M., Coelho-e-Silva, M., Valente-dos-Santos, J., Goncalves, R. S., Philippaerts, R., \& Malina, R. (2012). Scaling lower-limb isokinetic strength for biological maturation and body size in adolescent basketball players. European Journal of Applied Physiology, 112(8), 2881-2889.

Coelho, E. S. M. J., Figueiredo, A. J., Simoes, F., Seabra, A., Natal, A., Vaeyens, R., ... Malina, R. M. (2010). Discrimination of u-14 soccer players by level and position. International Journal of Sports Medicine, 31(11), 790-796.

Cohen, J. (1988). Statistical power analysis for the behavioral sciences Hillsdale: Lawrence Erlbaum.

Cunha, G., Lorenzi, T., Sapata, K., Lopes, A. L., Gaya, A. C., \& Oliveira, A. (2011). Effect of biological maturation on maximal oxygen uptake and ventilatory thresholds in soccer players: An allometric approach. Journal of Sports Sciences, 29(10), 1029-1039.

Cunha, G. S., Vaz, M. A., Geremia, J. M., Leites, G. T., Baptista, R. R., Lopes, A. L., \& Reischak-Oliveira, Á. (2016). Maturity status does not exert effects on aerobic fitness in soccer players after appropriate normalization for body size. Pediatric Exercise Science, 28(3), 456-465.

De Ste Croix, M., Deighan, M., \& Armstrong, N. (2003). Assessment and interpretation of isokinetic muscle strength during growth and maturation. Sports Medicine, 33(10), 727-743.

De Ste Croix, M. B., Armstrong, N., Welsman, J. R., \& Sharpe, P. (2002). Longitudinal changes in isokinetic leg strength in 10-14-year-olds. Annals of Human Biology, 29(1), 50-62.

Debernard, L., Robert, L., Charleux, F., \& Bensamoun, S. F. (2011). Characterization of muscle architecture in children and adults using magnetic resonance elastography and ultrasound techniques. Journal of Biomechanics, 44(3), 397-401.

Figueiredo, A. J., Coelho, E. S. M. J., \& Malina, R. M. (2011). Predictors of functional capacity and skill in youth soccer players. Scandinavian Journal of Medicine \& Science in Sports, 21(3), 446-454.

Figueiredo, A. J., Goncalves, C. E., Coelho, E. S. M. J., \& Malina, R. M. (2009). Youth soccer players, 11-14 years: Maturity, size, function, skill and goal orientation. Annals of Human Biology, 36(1), 60-73.

Forbes, H., Bullers, A., Lovell, A., McNaughton, L. R., Polman, R. C., \& Siegler, J. C. (2009a). Relative torque profiles of elite male youth footballers: Effects of age and pubertal development. International Journal of Sports Medicine, 30(8), 592-597.

Forbes, H., Sutcliffe, S., Lovell, A., McNaughton, L. R., \& Siegler, J. C. (2009b), Isokinetic thigh muscle ratios in youth football: Effect of age and dominance. International Journal of Sports Medicine, 30(8), 602-606.

Ford, P., De Ste Croix, M., Lloyd, R., Meyers, R., Moosavi, M., Oliver, J., ... Williams, C. (2011). The long-term athlete development model: Physiological evidence and application. Journal of Sports Sciences, 29(4), 389-402.

Fukunaga, Y., Takai, Y., Yoshimoto, T., Fujita, E., Yamamoto, M., \& Kanehisa, H. (2014). Effect of maturation on muscle quality of the lower limb muscles in adolescent boys. Journal of Physiological Anthropology, 33, 30.

Herzog, W., Sartorio, A., Lafortuna, C. L., Kanehisa, H., Fukunaga, T., Dotan, R., ... Perot, C. (2011). Commentaries on viewpoint: Can muscle size fully account for strength differences between children and adults? Journal of Applied Physiology, 110(6), 1750-1753.

Hoff, J., \& Helgerud, J. (2004). Endurance and strength training for soccer players: Physiological considerations. Sports Medicine, 34(3), 165-180.

Holm, l., Steen, H., \& Olstad, M. (2005). Isokinetic muscle performance in growing boys from pre-teen to maturity. An eleven-year longitudinal study. Isokinetics and Exercise Science, 13(2), 153-158.

Hopkins, W. G. (2000). Measures of reliability in sports medicine and science. Sports Medicine, 30(1), 1-15.
Hopkins, W. G., Marshall, S. W., Batterham, A. M., \& Hanin, J. (2009). Progressive statistics for studies in sports medicine and exercise science. Medicine and Science in Sports and Exercise, 41(1), 3-12.

Jaric, S. (2002). Muscle strength testing: Use of normalisation for body size. Sports Medicine, 32(10), 615-631.

Jaric, S. (2003). Role of body size in the relation between muscle strength and movement performance. Exercise and Sport Sciences Reviews, 31(1), 8-12.

Kanehisa, H., Muraoka, Y., Kawakami, Y., \& Fukunaga, T. (2003). Fascicle arrangements of vastus lateralis and gastrocnemius muscles in highly trained soccer players and swimmers of both genders. International Journal of Sports Medicine, 24(2), 90-95.

Kearns, C. F., Isokawa, M., \& Abe, T. (2001). Architectural characteristics of dominant leg muscles in junior soccer players. European Journal of Applied Physiology, 85(3-4), 240-243.

Kubo, K., Kanehisa, H., Kawakami, Y., \& Fukanaga, T. (2001). Growth changes in the elastic properties of human tendon structures. International Journal of Sports Medicine, 22(2), 138-143.

Maganaris, C. N., Baltzopoulos, V., Ball, D., \& Sargeant, A. J. (2001). In vivo specific tension of human skeletal muscle. Journal of Applied Physiology, 90(3), 865-872.

Malina, R. M., Eisenmann, J. C., Cumming, S. P., Ribeiro, B., \& Aroso, J. (2004). Maturity-associated variation in the growth and functional capacities of youth football (soccer) players 13-15 years. European Journal of Applied Physiology, 91(5-6), 555-562.

Marginson, V., \& Eston, R. (2001). The relationship between torque and joint angle during knee extension in boys and men. [Comparative Study]. Journal of Sports Sciences, 19(11), 875-880.

Miyatani, M., Kanehisa, H., Ito, M., Kawakami, Y., \& Fukunaga, T. (2004). The accuracy of volume estimates using ultrasound muscle thickness measurements in different muscle groups. European Journal of Applied Physiology, 91(2-3), 264-272.

Morse, C. I., Tolfrey, K., Thom, J. M., Vassilopoulos, V., Maganaris, C. N., \& Narici, M. V. (2008). Gastrocnemius muscle specific force in boys and men. Journal of Applied Physiology, 104(2), 469-474.

Nedeljkovic, A., Mirkov, D. M., Kukolj, M., Ugarkovic, D., \& Jaric, S. (2007). Effect of maturation on the relationship between physical performance and body size. The Journal of Strength and Conditioning Research, 21(1), 245-250.

Nevill, A. M., Holder, R. L., Baxter-Jones, A., Round, J. M., \& Jones, D. A. (1998). Modeling developmental changes in strength and aerobic power in children. Journal of Applied Physiology, 84(3), 963-970.

Nevill, A. M., Ramsbottom, R., \& Williams, C. (1992). Scaling physiological measurements for individuals of different body size. European Journal of Applied Physiology Occup Physiol, 65(2), 110-117.

O'Brien, T. D., Reeves, N. D., Baltzopoulos, V., Jones, D. A., \& Maganaris, C. N. (2009). Strong relationships exist between muscle volume, joint power and whole-body external mechanical power in adults and children. Experimental Physiology, 94(6), 731-738.

O'Brien, T. D., Reeves, N. D., Baltzopoulos, V., Jones, D. A., \& Maganaris, C. N. (2010a). In vivo measurements of muscle specific tension in adults and children. Experimental Physiology, 95(1), 202-210.

O'Brien, T. D., Reeves, N. D., Baltzopoulos, V., Jones, D. A., \& Maganaris, C. N. (2010b). Muscle-tendon structure and dimensions in adults and children. Journal of Anatomy, 216(5), 631-642.

Ostojic, S. M., Castagna, C., Calleja-Gonzalez, J., Jukic, I., Idrizovic, K., \& Stojanovic, M. (2014). The biological age of 14 -year-old boys and success in adult soccer: Do early maturers predominate in the top-level game? Research in Sports Medicine, 22(4), 398-407.

Philippaerts, R. M., Vaeyens, R., Janssens, M., Van Renterghem, B., Matthys, D., Craen, R., ... Malina, R.M. (2006). The relationship between peak height velocity and physical performance in youth soccer players. Journal of Sports Sciences, 24(3), 221-230.

Radnor, J. M., Oliver, J. L., Waugh, C. M., Myer, G. D., Moore, I. S., \& Lloyd, R. S. (2018). The influence of growth and maturation on stretch-shortening cycle function in youth. Sports Medicine, 48(1), 57-71.

Seymour, J. M., Ward, K., Sidhu, P. S., Puthucheary, Z., Steier, J., Jolley, C. J., ... Moxham, J. (2009). Ultrasound measurement of rectus 
femoris cross-sectional area and the relationship with quadriceps strength in COPD. Thorax, 64(5), 418-423.

Tanner, J. M. (1962). Growth at Adolescence (2nd ed., pp. 28-39). Oxford, UK: Blackwell.

Tonson, A., Ratel, S., Le Fur, Y., Cozzone, P., \& Bendahan, D. (2008). Effect of maturation on the relationship between muscle size and force production. Medicine \& Science in Sports \& Exercise, 40(5), 918-925.

Vaeyens, R., Malina, R. M., Janssens, M., Van Renterghem, B., Bourgois, J., Vrijens, J., \& Philippaerts, R. M. (2006). A multidisciplinary selection model for youth soccer: The Ghent youth soccer project. British Journal of Sports Medicine, 40(11), 928-934; discussion 934.

Valente-Dos-Santos, J., Coelho, E. S. M. J., Tavares, O. M., Brito, J., Seabra, A., Rebelo, A., ... Malina, R. M. (2015). Allometric modelling of peak oxygen uptake in male soccer players of 8-18 years of age. Annals Human Biology, 42(2), 125-133.
Valente-Dos-Santos, J., Sherar, L., Coelho, E. S. M. J., Pereira, J. R., Vaz, V., Cupido-Dos-Santos, A., ... Malina, R. M. (2013). Allometric scaling of peak oxygen uptake in male roller hockey players under 17 years old. Appl Physiol Nutr Metab, 38(4), 390-395.

Van Praagh, E., \& Dore, E. (2002). Short-term muscle power during growth and maturation. Sports Medicine, 32(11), 701-728.

Wrigley, R. D., Drust, B., Stratton, G., Atkinson, G., \& Gregson, W. (2014). Long-term soccer-specific training enhances the rate of physical development of academy soccer players independent of maturation status. International Journal of Sports Medicine, 35(13), 1090-1094.

Zoeller, R. F., Ryan, E. D., Gordish-Dressman, H., Price, T. B., Seip, R. L., Angelopoulos, T. J., ... Hoffman, E. P. (2008). Allometric scaling of isometric biceps strength in adult females and the effect of body mass index. European Journal of Applied Physiology, 104(4), 701-710. 